Contextualized Effects of Park Access and Usage on Residential Satisfaction: A Spatial Approach

Wenjie $\mathrm{WU}^{1}$,Guanpeng DONG ${ }^{2 *}$, Yeran $\mathrm{SUN}^{3,4}$, Yanwen YUN ${ }^{1}$

${ }^{1}$ College of Economics, Jinan University, No. 601 Huangpu Road West, Guangzhou, 510632, China. Email: wenjiewu@jnu.edu.cn

${ }^{2}$ Key Research Institute of Yellow River Civilization and Sustainable Development \& Collaborative Innovation Center for Yellow River Civilization, Henan University, Kaifeng, China. Email: gpdong henu@outlook.com

${ }^{3}$ School of Geography and Planning, Sun Yat-sen University, Guangzhou 510275, China

${ }^{4}$ Department of Geography, College of Science, Swansea University, Swansea SA28PP, United Kingdom. Email: yeran.sun@swansea.ac.uk

* Corresponding author:

Key Research Institute of Yellow River Civilization and Sustainable Development \& Collaborative Innovation Center for Yellow River Civilization, Henan University, 85 Minglun Street, Kaifeng, China. 475001.

Email: gpdong_henu@,outlook.com / guanpeng.dong@liverpool.ac.uk

This paper is submitted to Land Use Policy only. It has not been published previously, and it is not under consideration for publication elsewhere. Its publication is approved by all authors. 
Contextualized Effects of Park Access and Usage on Residential Satisfaction: A

\section{Spatial Approach}

Abstract: The spatial implications of urban parks on people's residential satisfaction are fueled by the desire to mitigate the rise of environmental injustice concerns in the developing world. While previous studies have examined the socio-spatial differentiation of park access and residential satisfaction, direct evidence on the role of park usage to play has been limited. This study shifts the focus from access to usage and quantitatively assess their associations with residential satisfaction. Our results quantify the evidence on the significant effects of park usage on residential satisfaction. Importantly, the association between park usage and residential satisfaction tends to be varied with local contextual amenities.

Keywords: Subjective well-being; park access and usage; spatial effects; multi-level models 


\section{Introduction}

Mega-city transformation in the post and transitional socialist countries suffers from urban greenness challenges, which affect people's quality of life. The distribution of urban parks is an important component of green infrastructure in cities and provides a range of perceived benefits for residents (Lee \& Maheswaran, 2011). In the traditional Western society, access to parks is seen as underlying channels for facilitating residents to gain healthy lifestyles and promotes residential satisfaction for urban inhabitants (Velarde, Fry, \& Tveit, 2007). Existing studies show that people's satisfaction assessment may be influenced by socioeconomic characteristics at both individual and neighborhood levels (Leslie, Sugiyama, Ierodiaconou, \& Kremer, 2010). Park usage and residential preference may further complicate the influences of park access on residential satisfaction. This is in line with theoretical arguments made by recent studies that residents sort themselves into places that can match with their preferences and are therefore satisfied (Cao \& Wang, 2016). Residents with high park usage frequencies are likely to choose to live in areas with close proximity to parks and thus may gain more subjective wellbeing benefits from park access. There is limited evidence on simultaneously considering the influences of park access and park usage in residential satisfaction within a transitional socialist country context.

The recent China's economic reforms marked a period of dramatic urban transformations that have brought great benefits but also great challenges for its citizens. The urban transformations have come alongside massive infrastructure investments and the gradual rise of social inequalities. The rapid urbanization in the post-reform urban China, however, imposes large environmental costs. The urban green infrastructure, such as parks are not distributed evenly within cities. The spatial distributions of parks in 
urban areas and green plots in individual communities have increased the public awareness for integrating park access and usage into the subjective evaluation of residential satisfaction, with the aim of achieving city livability development goals (Zhang, Yin, Zhang, Meng, \& Gao, 2006).

Using a cross-sectional individual survey data gathered in Beijing, this study explores the contextualized associations of park access, park usage and residential satisfaction. Respondents' detailed responses in the survey allow us to not just gauge park usage frequencies but also residential satisfaction perceptions. In terms of methodological innovations, we recognize that people living in adjacent neighborhoods may have experienced residential environments in a similar way due to spatial dependency. The existing literature on the evaluation of individual survey data has so far paid little attention to the role of spatial effects in the analysis (Ma, Chen, \& Dong, 2018). To address this spatial concern, we develop a multilevel model with spatially dependent random effects, implemented by using the Bayesian Markov chain Monte Carlo (MCMC) method, to obtain more reliable estimates on the impacts of park access and usage on residential satisfaction. Our spatial approach not just accounts for the two-level structure of the individual survey data where participants are nested into neighbourhoods (Jiedaos), but also consider the spatial effects into the estimation.

We limit our focus to a Chinese mega-city Beijing because it is at the forefront of high profile worldwide social media reports on the increasingly congested and polluted urban environment. The pressure to accommodate rapid urbanization and economic growth in Beijing over the recent thirty years means that urban residents can enjoy the better material standards of living while suffer from heavy environmental costs (Kahn \& Zheng, 2016). This paper is organized as follows: The next section discusses the 
conceptual framework pertaining to our theoretically-informed hypotheses. Section 3 describes the data and methods. Section 4 presents the results. Section 5 discusses the implications of this study. The final section concludes.

\section{Theoretical framework and literature review}

Residential satisfaction is an important element of individual's subjective wellbeing. It captures people's satisfied or dissatisfied perceptions of residential environments in matching with their expectations and experiences at the neighborhood (Campbell, Converse, \& Rodgers, 1976). Western research has long suggested that access to urban green space especially park access could generate residential satisfaction and health benefits through two underlying channels. First, park access could allow urban inhabitants to participate in physical activity, which contribute to subjective wellbeing and health benefits (Maas, Verheij, Groenewegen, de Vries, \& Spreeuwenberg, 2006). Adults with more access to parks are likely to be more active than those with limited access (Diez Roux, Evenson, McGinn, Brown, Moore, Brines, \& Jacobs, 2007). Recent studies in the environmental psychological literature have documented numerous wellbeing and health benefits gained through park access (e.g. Maas et al., 2006). Lack of park access has often been regarded as lack of opportunities for sites of social and physical activities, which is linked with people's wellbeing and health risk (Hartig, 2008; Grahn \& Stigsdotter, 2010). Second, sensing park access in itself may help residents to be more or less satisfied. For example, park access experience has been shown to promote the mental stress reduction (Woo, Tang, Suen, Leung, \& Wong, 2009). On a symbolic level, park access may affect people's satisfaction perceptions by providing a 'buffer' place in 
neighborhood built environments for social engagement (Kweon, Sullivan, \& Wiley, 1998), which in turn contributes to residents' sense of place.

The satisfaction implications of access to parks may vary with the size of parks (Giles-Corti, Broomhall, Knuiman, Collins, Douglas, Ng, Lange, \& Donovan, 2005) and neighborhood built environment characteristics. Distributive patterns of the association between park access and satisfaction may also have created the social and environmental inequality concerns in urban neighborhoods (Wolch, Byrne, \& Newell, 2014; Sister, Wolch, \& Wilson, 2010) that have experienced structural changes on the basis of the uneven distribution of public goods and services including parks. Previous studies suggest that the urban poor and minority social groups have less access to parks than White and affluent social groups (Dahmann, Wolch, Joassart-Marcelli, Reynolds, \& Jerrett, 2010). Boone, Buckley, Grove, and Sister (2009) find that Blacks are more likely than Whites to have better park access in terms of geographical distance, whereas Whites lived in places with access to larger park sizes. In addition, parks, if they are located in places with better access to other local amenities such as recreational facilities and transport links (Giles-Corti et al., 2005), are likely to generate differentiated subjective benefits for residents.

China has experienced phenomenal reforms from a centrally-planned economy to a market-oriented economy since the 1980s. The reforms have come alongside massive contextual changes in urban areas with the rise of inequalities of families and neighborhoods (Wang, 2004). In the post-reform era, several changes may be strengthening the differentiated relationships between park access and residential satisfaction. First, the gradual relaxation of effective constraints on rural to urban migration that apply under the Hukou household registration system has spurred the 
land-based urbanisation process (Chen \& Hu, 2015). Meantime, new patterns of socioresidential segregation ( $\mathrm{Li} \& \mathrm{Wu}, 2008$ ) between the urban affluent and the urban poor have intuitively led to the social concern about the equitable provision of access to urban parks (Xiao, Wang, Li, \& Tang, 2017). On the one hand, the maintenance and preservation of urban green space including parks are shadowed within Chinese planning intervention programs, but the planning of equitable park access has lagged behind rapid urbanisation. On the other hand, personal subjective satisfaction perceptions about residential environment have increasingly become respected and associated with the distribution of local public goods including parks in the post reform era (Zhang et al., 2006). In what are probably the most closely related papers to our own, Xiao et al (2017) look at the distributional effects of urban park access across space, and Wu et al (2019) explore the association between access to parks and satisfaction. On the surface, our research resembles the previous studies in Xiao et al (2017) and Wu et al (2019). We make a similar contextual setting for studying urban parks, but note that more careful consideration reveals differences between our work and other studies. For example, Xiao et al (2017) focused on evaluating justice concerns though measuring the spatial variation in accessessiblity of urban parks for residents with different socio-demgraphics at the local area level. While Wu et al (2019) considered the direct effect of access to urban parks on satisfaction with a particular residential domain, we look at the effects of park usage, and park access on overall satisfaction---a complementary inquiry. Methodologicially, we shift the focus from traditional logit methods towards assessing the robustness of the results to potential correlations between individual-level covariates and the neighbourhood-level unobservables using a multilevel model with spatially 
dependent random effects. This is also different from recent studies in this type of empirical applications in China.

Parks are heterogeneous in terms of its quality, design and location and are designed to serve diverse people and places for physical activity and recreational demands (Byrne \& Wolch, 2009). Such heterogeneity may hinder the equitable use of parks for all urban residents. (Byrne, 2012) posit that land use, segregated park systems and racial-minority group social composition could influence park access and use. Specifically, parks maybe unused by local residents due to their affiliated social environment and residential proximity. For example, residents may not use parks that are located in places with high concentration of crime rates and other disamenities (Gobster, 1998). From a dynamic perspective, Veitch, Ball, Crawford, Abbott, and Salmon (2012) find the substantial increases in park usage through a comparison of before and after the planning improvement programs in Victoria, Australia. In addition, it has been shown that residential proximity is associated with park usage and physical activity in parks, though this association varies across various social groups (Maas et al., 2006). In this view the environmental injustice concern is associated with not just park access but also park usage.

In recognition of the contextually dependent nature of park usage, our existing empirical knowledge about how residential preference may moderate the interactions of park access, park usage and satisfaction is limited in post-reform urban China. Residential preference indicates people self-select themselves into residential locations based on their preference towards residential environment. Much of the existing literature on the association between satisfaction and park access tended to be assessed without the explicit control for residential preference characteristics. Residential preference largely 
results from socio-demographics and perceptions toward the importance of residential environment in the decision-making of residential location choices. For example, residents with higher incomes tend to have more willingness to pay for living in places with better access to parks for self-rated health and well-being benefits. Sociodemographic characteristics such as age, gender and education attainment levels may also affect heterogeneous residential preference of urban parks and green space (Li, Zhang, Li, Kuzovkina, \& Weiner, 2015).

\section{Methodology}

\subsection{Data}

Our primary data were drawn from an individual survey conducted in metropolitan Beijing in 2013. The purposes of the survey were to assess residents' subjective evaluations of various facets of residential environments, and to assess the geography of subjective well-being in Beijing. The satisfaction perceptions were formed as the reflection of baseline wave of the Chinese City Livable Studies (Zhang et al., 2006; Ma et al., 2017). The target population of the survey were residents living in urban Beijing for at least six months. The survey adopted a stratified random sampling strategy. The survey was characterized by its sampling representativeness of the fundamental socio-demographics characteristics of Beijing city population (Ma et al., 2018). After excluding neighborhoods (Viedao) with limited observations and relevant data cleaning, 6,162 observations distributed in 115 neighborhoods were used for our analysis.

The variables contain several categories: satisfaction, park usage, park access, neighborhood built environment characteristics and individuals' socio-demographics. Primarily, we derive a respondent's neighbourhood satisfaction from survey questions 
on satisfaction with six specific dimensions of residential neighbourhood environment, i.e., physical location, living amenities, safety, socio-cultural setting, access to transport, and pollution. For each dimension, responses are measured on a five-point Likert scale from "very dissatisfied" (1) to "very satisfied" (5). The final overall residential satisfaction scores is calculated by averaging domain-specific scores following Ma et al. (2017). As an extension, this study analyses residential satisfaction about the greenness domain, which reflects participants' psychological responses to parks and is derived by using respondents' satisfaction statement about "how well parks and surrounding greenness conditions of their local residential environments meet their current satisfaction perceptions" in the survey. In terms of park usage, it was measured by using the park usage frequency of residents at weekends. In the survey the respondents were asked to report the frequencies they did activities in parks during weekends based on a threepoint Likert scale ranging from "never," "not quite often (once or twice per month)," and "quite often". Because only a small proportion of respondents reported "never" in park usage, they are combined with the "not quite often (once or twice per month)" into a single category for simplicity.

Following the previous literature (Cao and Wang, 2016), we use the residential preference statements to get a sense of whether respondents have explicitly given differential priorities in their residential choices. In the survey, respondents reported how true five statements are for their residential choices. These statements cover residential preference(RP) with: priority to dwelling comfort consideration (RP1); priority to choose residential locations with high property value appreciation potentials (RP2); priority to choose locations with high-end properties that can reflect high social status and class (RP3); priority to consider property price affordability (RP4); and 
priority to choose residential locations with good access to local amenities (RP5). Unfortunately the survey did not ask respondents to rank their preference in an ordinal scale. We understand that controlling for residential preference characteristics cannot fix the selection bias problem. As an additional robustness check, we make use of respondents' statement about whether they have experienced residential re-locations over the past five years ("movers") or they are long term residents in the current residence ("non-mover") to mitigate the residential self-selection effect (Cao \& Wang, 2016).

To measure spatial access of parks, we calculated the distance from each respondent's residential location to the nearest public park using ArcGIS. The spatial distributions of main public parks, urban ring roads and Jiedao boundaries in the study area were depicted in Figure 1. An initial exploration on the association between park access and residential satisfaction appeared to suggest a park access effect on residential satisfaction as illustrated in Figure 2. It plots the adjusted residential satisfaction scores against a series of distance-to-park bands $(\leq 0.5 \mathrm{~km}, 0.5-1 \mathrm{~km}, 1-1.5 \mathrm{~km}, 1.5-2 \mathrm{~km}$, and $\geq$ $2 \mathrm{~km}$ ), further differentiated between park usage frequency levels. ${ }^{1}$ There seems to be a decline in residential satisfaction when moving further away from a park. It is also interesting to notice that within close promity to green parks (the distance band of $\leq 0.5$ $\mathrm{km}$ ), frequent park use further increases the impact of park accessibility on residential satisfaction, a situation that does not apply to other distance bands.

\footnotetext{
${ }^{1}$ A multi-level model was implemented where residential satisfaction was regressed on the five distanceto-park band dummy variables, park use dummy variable, and their interaction terms. Individual-level socio-economics variables were also included in the model.
} 
[Figures 1 and 2 about here]

The neighborhood-level built environment variables were also incorporated in our analysis, including census-based population density, crime rate, and the proportion of historical buildings built before 1949. We measured access to key observable amenities such as primary schools and subway stations surrounding each respondent's residence, and access to the city centre using the ArcGIS. Accessibility to primary schools and subway stations was measured by the presence or the lack of presence of schools and subway stations within a 500 meters radius of each residence location. Changing the radius to $1 \mathrm{~km}$ did not change our key findings reported below. Finally, the survey includes individuals' socio-demographics such as age, income, family size, and educational attainment levels, which were used as control variables in our analysis because they were usually found to be significant correlates of residential satisfaction (e.g., Ma et al., 2017; Diener et al., 2018). Descriptions and summary statistics of key variables used in the study were reported in Table 1.

[Table 1 about here]

\subsection{Models}

Our modeling strategy accounts for the two-level structure of our suvey data where participants are nested into neighbourhoods (Jiedaos). We begin with a standard random intercept mulit-level model (MLM), which is specified as (Raudenbush \& Bryk, 2002; Goldstein, 2011),

$$
\begin{aligned}
& y_{i j}=\beta_{0, j}+\boldsymbol{\beta}_{1}^{T} \mathbf{x}_{i j}+\varepsilon_{i j}, i=1,2, \ldots, n_{j} ; j=1,2, \ldots, J \\
& \beta_{0, j}=\beta_{0}+\boldsymbol{\gamma}^{T} \mathbf{z}_{j}+\xi_{j}
\end{aligned}
$$


where $i$ and $j$ are individual and neighbourhood indicators, $y_{i j}$ refers to the satisfaction perceived by individual $i$ residing in neighbourhood $j$, and $n_{j}$ the sample size in neighbourhood $j$. The right hand side of the model comprises three components: $\beta_{0, j}$, the satisfaction level attributed to neighborhood characteristics or neighbourhood-level average satisfaction levels net of individual-level covariate effects; $\boldsymbol{\beta}_{1}^{T} \mathbf{x}_{i j}$, that explained by residents' characteristics such as socioeconomic factors, personal preferences, access to local amenities, park access and usage; $\varepsilon_{i j}$, the individual-level idiosyncratic error term following a Normal distribution $N\left(0, \sigma_{\varepsilon}^{2}\right)$. The level 2 model specifies the heterogeneous component $\beta_{0, j}$ as a sum of a constant intercept $\beta_{0}$, the part explained by neighborhood related variables $\mathbf{z}_{\mathbf{j}}$ such as crime rate and population, and a neighborhood specific error term $\xi_{j}$ following a Normal distribution $N\left(0, \sigma_{\xi}^{2}\right)$.

Substituting Equation (2) into Equation (1) gives a combined model specification,

$$
y_{i j}=\beta_{0}+\boldsymbol{\beta}_{1}^{T} \mathbf{x}_{i j}+\boldsymbol{\gamma}^{T} \mathbf{z}_{j}+\xi_{j}+\varepsilon_{i j}
$$

In our application context, the spatial indepdence assumption of unobserved neighourhood effects $(\xi)$ is not likely to hold. First, the geographical promixty effect might lead to spatial dependency or correlation in $\xi$, that is, neighbourhoods of close geographical proximity tend to have simiar levels of satisfaction, controlling for observed covariate effects or compositional effects (Haining, 2003; Dong \& Harris, 2015; Dong, Ma, Harris \& Pryce, 2016; Dong \& Wu, 2016; Ma et al., 2017). A simple spatial auto-correlation test on the independence of neighborhood-level averages of residential satisfaction yields a Moran' I statistic of 0.156 with a p-value less than 0.001 . Working with the neighborhood-level residuals obtained from a multi-level model with individual socioeconomics variables as predictors, the Moran's I statistic is still statistically significant. This suggests that the necessarity of relaxing the spatial independence assumption 
imposed on the unobserved neighourhood effects $(\xi)$. Second, individuals' satisfaction might be affected ont only by their immediate neighbourhoods (neighbourhoods where they reside) but also by surrounding neighbourhoods (LeSage \& Pace, 2009). Therefore, we posit a spatial simultaneous autoregressive model for $\xi$, as specified in Equation (4),

$$
\xi=\rho W \xi+\boldsymbol{\psi}
$$

where $W$ is a spatial weights matrix at the neighbourhood level, extracted based on geographical contiguity of neighoburhoods (Jiedaos). In our empirical analyses, spatial weights matrices based on the $k$ nearest neighbors scheme (where $k=5$ and 10) were also used (Haining, 2003), and estimation results remain similar to those reported below. $\rho$ quantifies the strength of spatial correlation in $\xi$, and $\boldsymbol{\psi}$ is a vector of idiosyncratic residuals, following a Normal distribution $N\left(0, \sigma_{\psi}^{2}\right)$. Combining Equations (3) and (4) gives the key modelling strategy employed in this study,

$$
\begin{gathered}
\boldsymbol{y}=X \boldsymbol{\beta}+\mathrm{Z} \boldsymbol{\gamma}+\Delta \xi+\boldsymbol{\varepsilon} \\
\xi=\rho W \xi+\boldsymbol{\psi}
\end{gathered}
$$

where $\Delta$ is a random effect design matrix with order of $\mathrm{N}\left(\sum_{j} n_{j}\right)$ by $J$, which simply assign random effect from the $j$-th neighbourhood $\left(\xi_{j}\right)$ to individuals located in it.

Following the convention in multilevel modelling, the neighbourhood level random error term $(\xi)$ is not correlated with individual-level covariates $X$. This could be a rather restrictive assumption and worth a careful testing in empirical studies. For instance, individuals with varying socio-economic status (e.g. income) or residential preferences could sort into different neighbourhoods based on neighbourhood characteristics. These factors are unobservable to researchers. We address such potential 
correlations between $X$ and $\xi$ by using the Mundlak correction method (Mundlak, 1978), the effectiveness of which has been demonstrated in both empirical (e.g. Ferrer-iCarbonell, 2005) and simulation studies (e.g. Bell \& Jones, 2015). The key idea of Mundlak correction is to add group means of individual-level covariates that are suspected to be correlated with the neighbourhood-level unobservables into the model, as in Equation (6),

$$
\boldsymbol{y}=X \boldsymbol{\beta}+\mathrm{Z} \boldsymbol{\gamma}+\bar{X} \boldsymbol{\delta}+\Delta \xi+\boldsymbol{\varepsilon}
$$

where $\bar{X}$ could be group means of a subset of the original individual-level covariates. After inserting $\bar{X}$, the regression coefficients of $\mathrm{X}, \boldsymbol{\beta}$, are now within-group estimators (Raudenbush \& Bryk, 2002). This is clearly seen by re-arranging Equation (6) as,

$$
\boldsymbol{y}=(X-\bar{X}) \boldsymbol{\beta}+\mathrm{Z} \boldsymbol{\gamma}+\bar{X}(\boldsymbol{\delta}+\boldsymbol{\beta})+\Delta \xi+\boldsymbol{\varepsilon}
$$

It is clear that the vector $(\delta+\beta)$ becomes between-group estimators and $\delta$ quantifies the differences between the within- and between-group associations between $X$ and $y$. More importantly, $\beta$ will be unbiased and consistent because the $(X-\bar{X})$ is uncorrelated with neighbourhood-level residuals, i.e., $\operatorname{cov}(X-\bar{X}, \xi)=0$ or $E[\xi \mid X-\bar{X}]=0$.

The model (Equation (5)) is implemented by using the Bayesian Markov chain Monte Carlo (MCMC) method. The full conditional posterior distributions for each model parameter are obtained by using the following formula,

$$
p\left(\boldsymbol{\beta}, \boldsymbol{\gamma}, \rho, \xi, \sigma_{\psi}^{2}, \sigma_{\varepsilon}^{2} \mid \boldsymbol{y}, X, W\right) \propto f\left(\boldsymbol{y} \mid \boldsymbol{\beta}, \boldsymbol{\gamma}, \xi, \sigma_{\varepsilon}^{2}, X\right) p\left(\xi \mid \rho, \sigma_{\psi}^{2}, W\right) p(\boldsymbol{\beta}) p(\boldsymbol{\gamma}) p\left(\sigma_{\psi}^{2}\right) p(\rho) p\left(\sigma_{\varepsilon}^{2}\right)
$$

where $f(y \mid$.$) is the data likelihood and prior densities of model parameters are denoted$ by p(.). Following Gelman et al. (2004), multivariate Normal distributions are specified 
for $p(\beta)$ and $p(\gamma)$, an uniform distribution over $(-1,1)$ for $p(\rho)$, and Inverse gamma (IG) distributions for $p\left(\sigma_{\psi}^{2}\right)$ and $p\left(\sigma_{\varepsilon}^{2}\right)$. The data likelihood is,

$$
f\left(\boldsymbol{y} \mid \boldsymbol{\beta}, \boldsymbol{\gamma}, \xi, \sigma_{\varepsilon}^{2}, X\right)=\left(2 \pi \sigma_{\varepsilon}^{2}\right)^{-N / 2} \exp \left\{\left(-2 \sigma_{\varepsilon}^{2}\right)^{-1}(y-X \boldsymbol{\beta}-\mathrm{Z} \boldsymbol{\gamma}-\Delta \xi)^{\prime}(y-X \boldsymbol{\beta}-\mathrm{Z} \boldsymbol{\gamma}-\Delta \xi)\right\}
$$

The full conditional posterior distributions for each model parameter are derived based on Equations (8) and (9) and the complete MCMC algorithms are avaialbe upon request. We have coded the MCMC samplers for model implementation using the R language and incorporated the code files into a open source R package HSAR (Dong, Harris \& Mimis, 2017). Statistical inferences of model parameters are based on two MCMC chains, each of which consisted of 10,000 iterations with a burn-in period of 5,000. To address the potential effects of different prior distributions set for model parameters (especially for the spatial auto-correlation parameter $\rho$ and the two variance parameters) on estimation results (Gelman et al., 2004; Shor et al., 2007), we implemented the models with different prior distributions. For instance, we specified a logitbeta prior distribution for $\rho$ with different hyperprior parameters: $\operatorname{logitbeta}(4,2)$ that favors medium spatial correlations and logitbeta $(0.5,0.5)$ that favors extremely large or small degree of spatial correlation (Ma et al. 2018). Model estimation results from these alternative prior distributions differ only marginally from the results reported below.

\section{Results}

\subsection{Baseline results}

Table 2 presents the baseline results from model specifications with various set of controls predicting residential satisfaction. The results from Model A and Model B are in 
favor of our basic presumption as greater access to parks is significantly associated with enhanced residential satisfaction of local residents. Higher weekend park use frequencies are associated with 0.039 points increase in residential satisfaction on a scale of 1 to 5 , everything else equal. Effects on residential satisfaction by living close to and frequent use of a park were not identified, as indicated by the statistically insignificant coefficients of the interaction terms between park access and park use.

Results from Model B (Table 2) further suggest that the impact of park access on residential satisfaction is likely to be depending on local amenities and neighborhood charactersitics. Several findings are worth noticing. First, the interaction term between park access and the access to subway station is statistically significant and the positive regression sign shows a potential complementary effect of better public transport access. That said, for respondents with good park access (residence-to-park distance $\leq 0.5 \mathrm{~km}$ ), good access to a subway station would be associated with a further 0.156 point increase in residential satisfaction. Second, neighbourhood crime appears to attenuate the association between good park access and residential satisfaction. This result is closely in line with the recent evidence that the park premium on property prices is significantly influenced by neighbourhood safty conditions or the park-safty complementarity (Albouy, Christensen \& Sarmiento-Barbieri, 2019). The park access effect (residence-topark distance $\leq 0.5 \mathrm{~km}$ ) would diminish to zero when neighbourhood crime rate reach about its mean value. ${ }^{2}$ The association between park access and residential satisfaction appears not be depending on geographical access to primary schools. Finally, the effects

\footnotetext{
${ }^{2}$ For simplicity in calculations, we assume away the interaction between park access and access to subway stations, the park access (residence-to-park distance $\leq 0.5 \mathrm{~km}$ ) effect on residential satisfaction is:

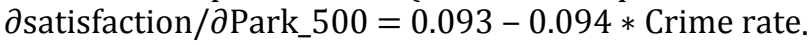


of local public amenities such as schools and subway stations on residential satisfaction are not clear. Whilst better access to subway stations is positively associated with higher residential satisfaction in Model A, this effect becomes insignificant in Model B when the interaction effects are considered. However, a significant and negative gradient in satisfaction is observed when moving away from the city center.

Estimates on the associations between socio-demographics and residential satisfaction are consistent with findings from previous literature (e.g., Blanchflower \& Oswald, 2004; Ma et al., 2018). Specifically, respondents with larger family sizes tend to report a significant lower level of residential satisfaction than those with small family sizes, everything else equal. Respondents with a tertiary educational qualification tend to be associated with a higher level of residential satisfaction than their counterparts. Women tend to report a lower residential satisfaction level than men do. There is clear evidence on the role of income levels to play in influencing residential satisfaction (Diener et al., 2018). In line with findings from Ma et al. (2018), homeowners are associated with a higher level of residential satisfaction when comparing to renters. Long-term residents are also found to be more satisfied than people who just relocated into the current neighborhood. Among the neighbourhood-level predictors, we find that living a neighbourhood with higher levels of violent crimes tend to decrease satisfaction levels.

With respect to structural model parameters, there are positive and significant spatial correlations in residential satisfaction at the neighbourhood scale, as indicated by the statistical significance of $\rho$. In addition, neighbourhood (Jiedao) accounts for about $6.5 \%$ of the total variation in residential satisfaction, after controlling for the included individual- and neighbourhood-level covariate effects. These results have two 
methodological implications. First, it is important to explicitly recognize the differences between neighbourhoods (or correlations between respondents located in the same neighbourhood) when modeling residential satisfaction. Multi-level modelling offers a useful tool for such purpose (Raudenbush \& Bryk, 2002; Goldstein, 2011). Second, the estimated significant spatial auto-correlation parameter confirms our specification of a spatially correlated neighbourhood-scale random effect ( $\xi)$. As a normal distribution is assumed for the neighbourhood-level residuals ( $\boldsymbol{\psi}$ in our spatially explicit multi-level), a commonly used Jarque-Bera test was conducted for each model specification (Snijders and Bosker, 2012). Test results suggested that the normality assumption cannot be rejected, implying the validity of the use of a multi-level modelling approach in the study.

\subsection{Heterogeneity effects and robustness checks}

Turning to the heterogeneity effects and robustness checks, we conjecture that the impacts of park access on residential satisfaction could vary with alternative outcome variables and social group strata. We test for our conjecture through a number of sensitivity analyses.

The first analysis considers alternative satisfaction outcomes. In Table 3 we report estimation results from models where we use the satisfaction with greenness as the outcome variable. While the mainstream literature have focused on overall residential satisfaction, some studies have explored satisfaction with a particular residential domain, such as satisfaction with travel (Cao, 2013). In this study, our key focus is neighborhoodlevel residential satisfaction, with the underlying assumption that neighborhood-level built environment design is of great relevance to people's living experience. We acknowledge people's satisfaction with greenness, along with other aspects of residential 
enviornments, is likely to correlate with overall residential satisfaction. Key model estimates with this alternative satisfaction outcome in Table 3 are similar to the baseline results (Table 2), and provide robust evidence of subjective wellbeing implications of park access and park usage in the spatial context. We do notice that the magnitudes of estimated regression coefficients of park access and its interaction with access to subway stations and crime differ between models with different outcome varibles. But directions and statistical inferences of these key variables remain the same.

Next, we focus on whether our conclusions are sensitive to the heterogeneity effects by social strata. The rationale behind this is that, we have so far concentrated on the population-level influences of park access and park usage on residential satisfaction. This focus might obscure a certain degree of heterogeneity across social dimensions. The social dimensions we explore are between high-income groups versus low-income groups and, between long-term residents and movers. Table 4 reports model estimation results by stratifying the analysis across these two dimensions. Columns 1-4 present results on the differentiated associations between park access, park usage and residential satisfaction among long-stay residents and residents who have recently moved in (nonmovers and movers here). It is noticeable that the associations between park access and use and residential satisfaction tends to be statistically significant for the non-mover group whilst neither are statistically significant for the movers samples. In addition, the interaction term between park access and access to subway stations is statistically significant for the non-movers group but not so for the movers group. We also group respondents into higher-income group if their monthly income is within the top two income bands, and lower-income group otherwise (Table 1). Model estimation results suggest that park access and use are statistically significantly associated with residential 
satisfaction for the relatively higher-income group but not so for the relatively lowerincome group. Turning to interactions between park access and other contextual factors, we find that interaction effect of park access and crime is only statistically significant for the higher-income group. These results reveal that using the population-level effects may overestimate or underestimate the influences of park access and use on residential satisfaction over a particular social dimension.

Finally, we consider issues relating to the potential correlations between individual-level covariates and neighborhood-level unobservables. We therefore, in Table 5, merge the Mundlak correction approach with our spatial multilevel model specifications. All the group-means of individual-scale covariates (socio-economics, park access and locational variables) and the corresponding interaction terms are included in the model (Bell and Jones, 2015). In doing so, estimates of regression coefficients of individual-level variables represent within-group estimators while regression coefficients of the group mean terms presents the differences between within-group and between-group estimators - $\delta$ in Equation (7) (Snijders and Bosker, 2012). Statistically significant regression coefficients of the group mean terms would suggest correlations between individual-level covariates and neighborhood-level unobservables, which is the essence of the classic Hausman econometric test (Snijders and Bosker, 2012). Among all the group-mean variables, only the regression coefficient of the group mean of Homeowners is statistically significant (reported in Table 5). Most importantly, estimates on park access, park use and interaction terms under key research interest remain very similar to the key results reported above (Table 2). We do notice slight decreases in the magnitudes of coefficients for park access, park use and the interaction term between park access and access to subway stations in the Mundlak correction model. These 
findings offer further assurance on the robustness of our analysis results as to how park access is associated with residential satisfaction and how such association may be affected by local amenities and neighbourhood attributes. Yet the estimates might not be precise enough for definitive conclusions because that there are many other social and spatial dimensions that may affect satisfaction but are beyond our consideration.

\section{Implications of this study}

The past decades have witnessed the rise of the "Healthy Cities" movement (Flynn, 1996) and how it has shaped the policy agenda towards promoting urban wellbeing (Wolch et al., 2014; Hughey, Walsemann, Child, Powers, Reed, \& Kaczynski, 2016). To place this movement in urban contexts, the contribution of park access to people's residential satisfaction is substantial. This is particularly the case in fast-urbanizing countries such as China where urban park infrastructure is in high demand but limited supply. On the one hand, the provision of parks affects residential preference and property market valuation as the rapid urbanization continues in Chinese megacities (Wu \& Dong, 2014; Wu, Dong, \& Zhang, 2017). On the other hand, differences in active life style across social groups may influence people's psychological satisfaction responses because park access and park usage pertaining to the ways that people valued active life style and aligned their varying degrees along residential satisfaction levels.

The preservation and development of public parks are costly projects. It is therefore important that urban planning decisions are informed by sound evidence. The findings presented in this study could be relevant for urban wellbeing and land uses in two central ways. First, subjective satisfaction consequences could be accounted for by park usage and residential preference effects as found in our analysis. In the presence of residential 
preference, our results suggest that social groups have placed different satisfaction perceptions, which partially reflect their differentiated social gradients. The transition to a market-oriented housing market has also created new opportunities of residential preference and lifted the costs on access to parks that were previously ignored by the socialist quota-based housing allocation system (Wang, 2004). Given the limited variation in air and water quality within a city, the distribution of public parks and private greenery amenities such as golf courses is crucial to influence subjective satisfaction and health (Lee \& Maheswaran, 2011; Wu et al., 2020) by offering the places for beneficial physical activity and social engagement opportunities (Maas et al., 2006). The spatial differentiated dimension of park access is important because the distributive spread of experiences and expectations towards park access might as well respond more vigorously to improvements in urban parks. From a dynamic perspective, for example, it would be more worthwhile to look at the before-and-after comparison of influences of the opening of the new Olympic park in Beijing on people's satisfaction. This warrants further studies.

The second and alternative way of rethinking the planning implication of our study is the interpretation of effects of park access and park usage in affecting residential satisfaction. Our results clarify the importance of considering the complementary effects between park usage and access to other contextual amenities in the evaluations of subjective wellbeing by residents. Planners' mindsets apparently are encouraged to adopt the "nonlinear" thinking through a comprehensive landscape design in a given neighborhood or district. In doing so, people will be able to access to a diversified composition of living-working-leisure amenities and be attracted to use these amenities within a reasonable spatial buffer. Planners should go beyond conventional accessibility 
measures in assessing the satisfaction impact of parks and incorporate the usage and quality of parks into the landscape design so as to maximize the residential exposure of parks for residents. In this sense, the landscape design to delineating the usage, quality and accessibility of parks is important for land use policy interventions.

\section{Conclusions}

Our analysis presents the evidence that the spatial access of parks has generated subjective wellbeing implications. This is in conjunction with previous research on wellbeing attenuation by urban green space (Li et al., 2015), in the sense that living closer to parks is associated with enhanced satisfaction. In addition, park usage frequency is an important correlate of satisfaction outcomes. We further disentangle the channels resulting in this association. In particular, unequal access to parks represents urban environmental injustice across different social groups for achieving subjective wellbeing benefits. Thus people's relative position across social dimensions is important for residential satisfaction in post-reform urban China.

This study has several limitations that are inherently tied to the cross-sectional data nature. First, it would be useful to test for differences in park usage frequencies at both weekdays and weekends. It is also important to control for seasonal or weather effects on park usage of residentsm at fine temporal scales. The survey did not provide such information. These warrant further studies. Second, the natural environment of city landscape derived from spatial coverage of parks, lawns, rivers, forests and plots of green spaces in individual communities can be considered as a more general setting of urban greenness. Due to the lack of data, we are not able to test for the possibility that people's satisfaction consequences are driven by other observable and unobservable green 
infrastructure. Further, the survey mainly focuses on working populations. We are unable to consider the impact of park usage on junior residents aged below 16 or retired people aged above 60, who are likely to be potential park users as well. When longitudinal data are available, future work should measure how changes in individuals' satisfaction response to improvements in urban green infrastructure in order to provide a more complete understanding of the causal mechanisms underlying dynamics of people's satisfaction perceptions. 
Acknowledgement: We thank the editor and reviewers for helpful comments. This work was supported by the National Natural Science Foundation of China (41971194), and the Research Center for the Industrial Development of Guangdong and its Regional Cooperation with Hong Kong, Macau and Taiwan.

\section{References}

Abou-Zeid, M, Witter, R., Bierlaire, M., Kaufmann, V., \& Ben-Akiva, M. (2012). Happiness and Travel Mode Switching: Findings from a Swiss Public Transportation Experiment. Transport Policy, 19, 93-104.

Albouy, D., Christensen, P., \& Sarmiento-Barbieri, I. (2019). Unlocking amenities: estimating public good complementarity. NBER Working paper 25107. Available at https://www.nber.org/papers/w25107.pdf

Bell, A. J., \& Jones, K. (2015). Explaining Fixed Effects: Random Effects Modeling of Time-Series CrossSectional and Panel Data. Political Science Research \& Methods, 3, 133-153.

Blanchflower, D. G., \& Oswald, A. J. (2004). Well-being over time in Britain and the USA. Journal of Public Economics, 88, 1359-1386.

Boone, C. G., Buckley, G. L., Grove, J. M., \& Sister, C.. (2009). Parks and People: An Environmental Justice Inquiry in Baltimore, Maryland. Annals of the Association of American Geographers, 99, 767-787.

Byrne, J. (2012). When Green Is White: The Cultural Politics of Race, Nature and Social Exclusion in a Los Angeles Urban National Park. Geoforum, 43, 595-611.

Byrne, J., \& Wolch, J. (2009). Nature, Race, and Parks: Past Research and Future Directions for Geographic Research. Progress in Human Geography, 33, 743-765.

Campbell, A., Converse, P. E., \& Rodgers, W. L. (1976). The Quality of American Life: Perceptions, Evaluations, and Satisfactions. Russell Sage Foundation.

Cao, X., \& Wang, D. (2016). Environmental Correlates of Residential Satisfaction: An Exploration of Mismatched Neighborhood Characteristics in the Twin Cities. Landscape and Urban Planning 150, 26-35.

Cao, X. (2013). The association between light rail transit and satisfactions with travel and life: evidence from twin cities. Transportation, 40, 921-933.

Chen, Y., \& Hu, Z. X.. (2015). Producing Nature for Public: Land-Based Urbanization and Provision of Public Green Spaces in China. Applied Geography, 58, 32-40.

Dahmann, N., Wolch, J., Joassart-Marcelli, P., Reynolds, K., \& Jerrett, M. (2010). The Active City? Disparities in Provision of Urban Public Recreation Resources. Health \& Place, 16, 431-445.

Diener, E., Oishi, S., \& Tay, L. (2018). Advances in subjective well-being research. Nature Human Behaviour, 2, 253-260.

Diez Roux, A. V., Evenson, K. R., McGinn, A. P., Brown, D. G., Moore, L., Brines, S., \& Jacobs, D. R. (2007). Availability of Recreational Resources and Physical Activity in Adults. American Journal of Public Health 97, 493-499.

Dong, G., \& Harris, R. (2015). Spatial autoregressive models for geographically hierarchical data structures. Geographical Analysis, 47, 173-191.

Dong, G., Ma, J., Harris, R., \& Pryce, G. (2016). Spatial Random Slope Multilevel Modeling Using Multivariate Conditional Autoregressive Models: A Case Study of Subjective Travel Satisfaction in Beijing. Annals of the American Association of Geographers, 106: 19-35.

Dong, G., \& Wu, W. (2016). Schools, land markets and spatial effects. Land Use Policy, 59, 366-374.

Dong, G., Harris, R., \& Mimis, A. (2017). HSAR: Hierarchical Spatial Autoregressive Model. R package version 0.4.2, URL. https://cran.r-project.org/web/packages/HSAR/index.html

Ferrer-i-Carbonell, A. (2005). Income and well-being: an empirical analysis of the comparison income effect. Journal of Public Economics, 89, 997-1019. 
Flynn, B. C. (1996). Healthy Cities: Toward Worldwide Health Promotion. Annual Review of Public Health, 17, 299-309.

Giles-Corti, B., Broomhall, M. H., Knuiman, M., Collins, C., Douglas, K., Ng, K., Lange, K., \& Donovan, R. J. (2005). Increasing Walking: How Important Is Distance to, Attractiveness, and Size of Public Open Space? American Journal of Preventive Medicine, 28, 169-176.

Gobster, P. H. (1998). Urban Parks as Green Walls or Green Magnets? Interracial Relations in Neighborhood Boundary Parks. Landscape and Urban Planning, 41, 43-55.

Goldstein, H. (2011). Multilevel statistical models. John Wiley \& Sons.

Grahn, P., \& Stigsdotter, U. K. (2010). The Relation Between Perceived Sensory Dimensions of Urban Green Space and Stress Restoration. Landscape and Urban Planning, 94, 264-275.

Haining, R. P. (2003). Spatial data analysis: theory and practice. Cambridge University Press.

Hartig, T. (2008). Green Space, Psychological Restoration, and Health Inequality. The Lancet 372, 16141615.

Hughey, S. M., Walsemann, K. M., Child, S., Powers, A., Reed, J. A., \& Kaczynski, A. T. (2016). Using an Environmental Justice Approach to Examine the Relationships Between Park Availability and Quality Indicators, Neighborhood Disadvantage, and Racial/Ethnic Composition. Landscape and Urban Planning, $148,159-169$.

Kahn, M. E., \& Zheng, S. (2016). Blue Skies over Beijing: Economic Growth and the Environment in China. Princeton University Press.

Kweon, B-S., Sullivan, W. C., \& Wiley, A. R. (1998). Green Common Spaces and the Social Integration of InnerCity Older Adults. Environment and Behavior, 30, 832-858.

Lee, A., \& Maheswaran, R. (2011). The Health Benefits of Urban Green Spaces: A Review of the Evidence. Journal of Public Health 33, 212-222.

LeSage, J., \& Pace, R. K. (2009). Introduction to spatial econometrics. CRC Press.

Leslie, E., Sugiyama, T., Ierodiaconou, D., \& Kremer, P. (2010). Perceived and Objectively Measured Greenness of Neighbourhoods: Are They Measuring the Same Thing? Landscape and Urban Planning 95, 28-33.

Li, X., Zhang C., Li, W., Kuzovkina, Y. A., \& Weiner, D. (2015). Who Lives in Greener Neighborhoods? The Distribution of Street Greenery and Its Association with Residents' Socioeconomic Conditions in Hartford, Connecticut, USA. Urban Forestry \& Urban Greening, 14, 751-759.

Li, Z., \& Wu, F. L. (2008). Tenure-Based Residential Segregation in Post-Reform Chinese Cities: A Case Study of Shanghai. Transactions of the Institute of British Geographers, 33, 404-419.

Ma, J., Chen, Y., \& Dong, G. (2018). Flexible Spatial Multilevel Modeling of Neighborhood Satisfaction in Beijing. The Professional Geographer, 70, 11-21.

Ma, J., Mitchell, G., Dong, G., \& Zhang, W. (2017). Inequality in Beijing: A Spatial Multilevel Analysis of Perceived Environmental Hazard and Self-Rated Health. Annals of the American Association of Geographers, 107, 109-129.

Maas, J., Verheij, R. A., Groenewegen, P., de Vries, S., \& Spreeuwenberg, P. (2006). Green Space, Urbanity, and Health: How Strong Is the Relation? Journal of Epidemiology and Community Health 60, 587-592.

Mundlak, Y. (1978). On the pooling of time series and cross section data. Econometrica, 46, 69-85.

Raudenbush, S. W., \& Bryk, A. S. (2002). Hierarchical linear models: Applications and data analysis methods. Sage.

Sister, C., Wolch, J., \& Wilson, J. (2010). Got Green? Addressing Environmental Justice in Park Provision. GeoJournal, 75, 229-248.

Snijders, T. A. B \& Bosker, R. (2012). Multilevel analysis: an introduction to basic and advanced multilevel modelling. Sage London.

Veitch, J., Ball, K., Crawford, D., Abbott, G. R., \& Salmon, J. (2012). Park Improvements and Park Activity: A Natural Experiment. American Journal of Preventive Medicine, 42, 616-619. 
Velarde, M. D., Fry, G., Tveit, M. (2007). Health Effects of Viewing Landscapes-Landscape Types in Environmental Psychology. Urban Forestry \& Urban Greening, 6, 199-212.

Wang, Y. P. (2004). Urban Poverty, Housing and Social Change in China. Routledge.

Wolch, J. R., Byrne, J., \& Newell, J. P. (2014). Urban Green Space, Public Health, and Environmental Justice: The Challenge of Making Cities 'Just Green Enough'. Landscape and Urban Planning, 125, 234-244.

Woo, J., Tang, N., Suen, E., Leung, J., \& Wong, M. (2009). Green Space, Psychological Restoration, and Telomere Length. The Lancet, 373, 299-300.

Wu, W., \& Dong, G. (2014). Valuing the 'Green' Amenities in a Spatial Context. Journal of Regional Science, 54, 569-585.

Wu, W., Dong, G., \& Zhang, W. (2017). The Puzzling Heterogeneity of Amenity Capitalization Effects on Land Markets. Papers in Regional Science, 96, 135-153.

Wu, W., Wang, M., Zhu, N., et al. (2019). Residential Satisfaction about Greenness: Heterogeneous Effects across Social and Spatial Gradients, Urban forestry \& Urban Greening, 38,133-144.

Wu, W., Chen, Y., Liu, Y. (2020). Perceived spillover effects of club-based green space: Evidence from Beijing golf courses, China", Urban Forestry \& Urban Greening, 48, 126518.

Xiao, Y., Wang, Z., Li, Z., \& Tang, Z. (2017). An Assessment of Urban Park Access in Shanghai - Implications for the Social Equity in Urban China. Landscape and Urban Planning 157, 383-393.

Zhang, W., Yin, W., Zhang, J., Meng, B, \& Gao, X. (2006). A Study of Livable Cities in China (Beijing). Social Sciences Academic Press: Beijing, China. 


\section{List of tables}

Table 1. Variable description and summary statistics.

Table 2. Model estimation results for overall residential satisfaction.

Table 3. Model estimation results for satisfaction with greenness.

Table 4. Estimation results on heterogeneity effects by social dimensions.

Table 5. Estimation results from models with the Mundlak correction. 
Table 1. Variable description and summary statistics.

\begin{tabular}{lll}
\hline Variable names & Descriptions & Summaries \\
\hline Satisfaction & Overall satisfaction scores (one to five) & 3.15 \\
& Satisfaction with greenness (one to five) & 3.41 \\
Park access & Distance to the nearest park & \\
Park_500 & within 500 m & $9.4 \%$ \\
Park_1000 & Between 500 m to 1 km & $18.1 \%$ \\
Park use & Park visit frequency (1 = often, 0 = not often or never) & $19.8 \%$ \\
Subway & Residence-to-subway station distance within 500 m & $16.1 \%$ \\
School & Residence-to-primary school distance within 500 m & $35.7 \%$ \\
CBD & Distance to the city centre & $6.73 \mathrm{~km}$ \\
Neighbourhood characteristics & \\
Crime rate & Violent crime counts per 10,000 population in 2010 \\
Population & Population density (1,000 persons per km ${ }^{2}$ ) & 1.04 \\
Buildings1949 & Proportion of historical buildings built before 1949 & 28.8 \\
Individual-level socio-demographics & $5.1 \%$ \\
Family size & Number of family members & \\
Gender & Male as baseline category & 2.61 \\
Age ( $\leq 30)$ & Age below 30 & $51 \%$ \\
Age (30-39) & Age between 30 and 39 & $43.4 \%$ \\
Age (40-49) & Age between 40 and 49 & $23.6 \%$ \\
Age ( $\geq 50)$ & Age above 50 & $22.4 \%$ \\
Primary & Primary education qualification & $10.6 \%$ \\
Secondary & Secondary education qualification & $6.81 \%$ \\
Tertiary & Tertiary education qualification \\
Income ( $\leq 3,000)$ & Monthly income below 3000 RMB & $27.1 \%$ \\
Income (3,000-4,999) & Monthly income between 3,000 and 4,999 RMB \\
Income (5,000-9,999) & Monthly income between 5,000 and 9,999 RMB & $66 \%$ \\
Income ( $\geq 9,999)$ & Monthly income above 10,000 RMB & $26 \%$ \\
Homeowners & Renters as baseline category & $38.3 \%$ \\
Movers & Living in the current residence for less than 5 years & $27.5 \%$ \\
\hline & & $8.3 \%$ \\
& & $51.2 \%$ \\
& & $47.2 \%$ \\
\hline
\end{tabular}


Table 2. Model estimation results for overall residential satisfaction.

\begin{tabular}{|c|c|c|c|c|}
\hline & \multicolumn{2}{|l|}{ Model $A$} & \multicolumn{2}{|l|}{ Model B } \\
\hline & Estimates & Std.error & Estimates & Std.error \\
\hline Intercept & $3.115^{*}$ & 0.069 & $3.117^{*}$ & 0.069 \\
\hline Park_500 & $0.086^{*}$ & 0.042 & $0.093^{*}$ & 0.041 \\
\hline Park_1000 & $0.063 *$ & 0.028 & 0.035 & 0.066 \\
\hline Park_500 $\times$ Park use & 0.094 & 0.073 & 0.102 & 0.073 \\
\hline Park_1000 $\times$ Park use & 0.015 & 0.049 & 0.009 & 0.049 \\
\hline Park use & $0.039 *$ & 0.018 & $0.04 *$ & 0.018 \\
\hline Subway & $0.040^{*}$ & 0.020 & 0.028 & 0.022 \\
\hline School & -0.022 & 0.019 & -0.039 & 0.021 \\
\hline CBD & $-0.089 *$ & 0.031 & $-0.092 *$ & 0.031 \\
\hline Family size & $-0.016^{*}$ & 0.007 & $-0.016^{*}$ & 0.007 \\
\hline Gender & $-0.03 *$ & 0.013 & $-0.03 *$ & 0.013 \\
\hline Age (30-39) & -0.03 & 0.018 & -0.031 & 0.018 \\
\hline Age (40-49) & $-0.098 *$ & 0.019 & $-0.098^{*}$ & 0.019 \\
\hline Age $(\geq 50)$ & $-0.121 *$ & 0.025 & $-0.12 *$ & 0.025 \\
\hline Income $(3,000-4,999)$ & $0.073 *$ & 0.017 & $0.074 *$ & 0.017 \\
\hline Income $(5,000-9,999)$ & $0.155^{*}$ & 0.020 & $0.154^{*}$ & 0.020 \\
\hline Income $(\geq 9,999)$ & $0.251^{*}$ & 0.028 & $0.25 *$ & 0.028 \\
\hline Secondary & 0.024 & 0.029 & 0.024 & 0.029 \\
\hline Tertiary & $0.064 *$ & 0.029 & $0.064 *$ & 0.029 \\
\hline Movers & $-0.034 *$ & 0.014 & $-0.033^{*}$ & 0.014 \\
\hline Homeowners & $0.059^{*}$ & 0.016 & $0.06^{*}$ & 0.016 \\
\hline Population & 0.001 & 0.015 & 0.002 & 0.015 \\
\hline Buildings 1949 & 0.009 & 0.156 & 0.025 & 0.156 \\
\hline Crime rate & $-0.04 *$ & 0.018 & $-0.039^{*}$ & 0.019 \\
\hline Park_500 $\times$ Subway & & & $0.156^{*}$ & 0.067 \\
\hline Park_1000 $\times$ Subway & & & 0.034 & 0.052 \\
\hline Park_500 $\times$ School & & & 0.097 & 0.069 \\
\hline Park_1000 $\times$ School & & & 0.061 & 0.046 \\
\hline Park_500 $\times$ Crime rate & & & $-0.094^{*}$ & 0.041 \\
\hline Park_1000 $\times$ Crime rate & & & -0.016 & 0.046 \\
\hline Preferences variables & Yes & & Yes & \\
\hline$\rho$ & $0.459 *$ & 0.159 & $0.429^{* *}$ & 0.169 \\
\hline$\sigma_{\varepsilon}^{2}$ & 0.258 & 0.004 & 0.258 & 0.005 \\
\hline$\sigma_{\xi}^{2}$ & 0.018 & 0.003 & 0.019 & 0.003 \\
\hline Sample size & 6162 & & 6162 & \\
\hline Jarque-Bera test & $1.757(\mathrm{P}-\mathrm{V}$ & f 0.338$)$ & $1.789(\mathrm{P}-\mathrm{v}$ & e of 0.338 ) \\
\hline
\end{tabular}

Note: the symbol "** represents statistical significance levels of $5 \%$ or better. Standard errors of estimates are calculated as the standard deviation of posterior samples of each parameter. 
Table 3. Model estimation results for satisfaction with greenness.

\begin{tabular}{lllll}
\hline & Model C & & Model D \\
\hline & Estimates & Std.error & Estimates & Std.error \\
\hline Intercept & $3.347^{*}$ & 0.081 & $3.331^{*}$ & 0.078 \\
Park_500 & $0.131^{*}$ & 0.059 & $0.252^{*}$ & 0.101 \\
Park_1000 & $0.128^{*}$ & 0.043 & 0.153 & 0.105 \\
Park_500 $\times$ Park use & 0.001 & 0.132 & 0.017 & 0.132 \\
Park_1000 $\times$ Park use & 0.012 & 0.088 & 0.008 & 0.089 \\
Park use & $0.082^{*}$ & 0.033 & $0.085^{*}$ & 0.033 \\
Subway & 0.046 & 0.033 & 0.033 & 0.037 \\
School & -0.049 & 0.031 & -0.066 & 0.034 \\
CBD & 0.020 & 0.032 & 0.011 & 0.032 \\
Crime rate & $-0.046^{*}$ & 0.017 & $-0.049^{*}$ & 0.018 \\
Park_500 $\times$ Subway & & & $0.044^{*}$ & 0.019 \\
Park_1000 $\times$ Subway & & & 0.055 & 0.089 \\
Park_500 $\times$ School & & & -0.043 & 0.120 \\
Park_1000 $\times$ School & & & 0.126 & 0.079 \\
Park_500 $\times$ Crime rate & & & $-0.112^{*}$ & 0.051 \\
Park_1000 $\times$ Crime rate & & & 0.078 & 0.072 \\
Full control variables & Yes & 0.159 & Yes & \\
$\rho$ & $0.419 *$ & 0.005 & 0.241 & 0.169 \\
$\sigma_{\varepsilon}^{2}$ & 0.241 & 0.006 & 0.014 & 0.005 \\
$\sigma_{\xi}^{2}$ & 0.015 & & 6162 & \\
Sample size & 6162 & 0.006 \\
Jarque-Bera test & $1.056(\mathrm{P}$-value of 0.524$)$ & $0.975(\mathrm{P}-\mathrm{value}$ of 0.57$)$ \\
\hline
\end{tabular}

Note: the symbol "*” represents statistical significance levels of $5 \%$ or better. Standard errors of estimates are calculated as the standard deviation of posterior samples of each parameter. Preference variables are part of the full control variable list. 
Table 4. Estimation results on heterogeneity effects by social dimensions.

\begin{tabular}{|c|c|c|c|c|c|c|c|c|}
\hline & \multicolumn{2}{|c|}{ Movers samples } & \multicolumn{2}{|c|}{ Non-movers samples } & \multicolumn{2}{|c|}{ Lower-income samples } & \multicolumn{2}{|c|}{ Higher-income samples } \\
\hline & Estimates & Std.error & Estimates & Std.error & Estimates & Std.error & Estimates & Std.error \\
\hline Intercept & $3.075^{*}$ & 0.090 & $3.064 *$ & 0.085 & $3.237^{*}$ & 0.112 & $3.174 *$ & 0.080 \\
\hline Park_500 & -0.164 & 0.151 & $0.291 *$ & 0.135 & -0.063 & 0.151 & $0.193 *$ & 0.089 \\
\hline Park_1000 & -0.03 & 0.099 & 0.110 & 0.085 & -0.106 & 0.102 & 0.12 & 0.084 \\
\hline Park_500* Park use & $0.301 *$ & 0.130 & -0.041 & 0.091 & 0.156 & 0.117 & 0.041 & 0.094 \\
\hline Park_1000* Park use & -0.063 & 0.078 & 0.061 & 0.064 & 0.026 & 0.077 & 0.009 & 0.064 \\
\hline Park use & -0.004 & 0.026 & $0.089 *$ & 0.026 & 0.025 & 0.029 & $0.055^{*}$ & 0.024 \\
\hline Subway & 0.02 & 0.032 & 0.04 & 0.031 & 0.065 & 0.036 & 0.001 & 0.028 \\
\hline School & -0.041 & 0.031 & -0.03 & 0.028 & -0.022 & 0.033 & -0.047 & 0.027 \\
\hline CBD & -0.078 & 0.040 & $-0.077^{*}$ & 0.038 & -0.033 & 0.045 & $-0.121 *$ & 0.036 \\
\hline Crime rate & $-0.041 *$ & 0.019 & -0.027 & 0.025 & $-0.04^{*}$ & 0.019 & $-0.036^{*}$ & 0.015 \\
\hline Park_500* Subway & 0.159 & 0.142 & $0.168 *$ & 0.079 & 0.056 & 0.122 & $0.238 *$ & 0.112 \\
\hline Park_1000* Subway & -0.089 & 0.082 & 0.12 & 0.067 & -0.128 & 0.082 & 0.111 & 0.066 \\
\hline Park_500* School & 0.067 & 0.108 & 0.082 & 0.092 & 0.04 & 0.107 & 0.140 & 0.089 \\
\hline Park_1000* School & 0.036 & 0.073 & 0.043 & 0.060 & 0.038 & 0.076 & 0.058 & 0.058 \\
\hline Park_500* Crime rate & 0.146 & 0.127 & $-0.218^{*}$ & 0.101 & 0.068 & 0.127 & $-0.168 *$ & 0.067 \\
\hline Park_1000* Crime rate & 0.056 & 0.074 & -0.066 & 0.058 & $0.146^{*}$ & 0.072 & -0.094 & 0.056 \\
\hline Full control variables & Yes & & Yes & & Yes & & Yes & \\
\hline$\sigma_{\varepsilon}^{2}$ & 0.25 & 0.007 & 0.258 & 0.007 & 0.237 & 0.007 & 0.265 & 0.006 \\
\hline$\sigma_{\xi}^{2}$ & 0.021 & 0.004 & 0.022 & 0.004 & 0.023 & 0.005 & 0.022 & 0.005 \\
\hline Sample size & \multicolumn{2}{|l|}{2908} & \multicolumn{2}{|l|}{3254} & \multicolumn{2}{|l|}{3957} & \multicolumn{2}{|l|}{2205} \\
\hline Jarque-Bera test & \multicolumn{2}{|c|}{$0.068(\mathrm{P}$-value of 0.971$)$} & \multicolumn{2}{|c|}{0.584 (P-value of 0.732$)$} & \multicolumn{2}{|c|}{0.975 (P-value of 0.57$)$} & \multicolumn{2}{|c|}{$1.325(\mathrm{P}$-value of 0.451$)$} \\
\hline
\end{tabular}

Note: the symbol “*” represents statistical significance levels of $5 \%$ or better. Standard errors of estimates are calculated as the standard deviation of posterior samples of each parameter. 
Table 5. Estimation results from models with the Mundlak correction.

\begin{tabular}{|c|c|c|}
\hline & Estimates & Std.error \\
\hline Intercept & 1.386 & 0.816 \\
\hline \multicolumn{3}{|l|}{ Within-group estimators } \\
\hline Park_500 & $0.082 *$ & 0.039 \\
\hline Park_1000 & 0.003 & 0.069 \\
\hline Park_500 $\times$ Park use & 0.099 & 0.073 \\
\hline Park_1000 $\times$ Park use & 0.013 & 0.049 \\
\hline Park use & $0.038^{*}$ & 0.018 \\
\hline Subway & 0.022 & 0.023 \\
\hline School & -0.041 & 0.022 \\
\hline CBD & $-0.184^{*}$ & 0.058 \\
\hline Homeowners & $0.056^{*}$ & 0.016 \\
\hline Population & 0.001 & 0.019 \\
\hline Buildings 1949 & 0.068 & 0.203 \\
\hline Crime rate & $-0.037 *$ & 0.018 \\
\hline Park_500 $\times$ Subway & $0.153^{*}$ & 0.071 \\
\hline Park_1000 $\times$ Subway & 0.037 & 0.052 \\
\hline Park_500 $\times$ School & 0.106 & 0.070 \\
\hline Park_1000 $\times$ School & 0.073 & 0.047 \\
\hline Park_500 $\times$ Crime rate & $-0.098 *$ & 0.044 \\
\hline Park_1000 $\times$ Crime rate & -0.001 & 0.050 \\
\hline \multicolumn{3}{|c|}{ Estimates for group mean variables } \\
\hline Homeowners & $0.279^{*}$ & 0.138 \\
\hline Preference variables & Yes & \\
\hline Other group mean variables & Yes & \\
\hline$\rho$ & $0.469^{* *}$ & 0.129 \\
\hline$\sigma_{\varepsilon}^{2}$ & 0.258 & 0.006 \\
\hline$\sigma_{\xi}^{2}$ & 0.015 & 0.004 \\
\hline Sample size & 6162 & \\
\hline Jarque-Bera test & $2.841(\mathrm{P}-\mathrm{v}$ & \\
\hline
\end{tabular}

Note: the symbol "*" represents statistical significance levels of $5 \%$ or better. Standard errors of estimates are calculated as the standard deviation of posterior samples of each parameter. We only report the statistically significant regression coefficient for a set of group mean variables. 


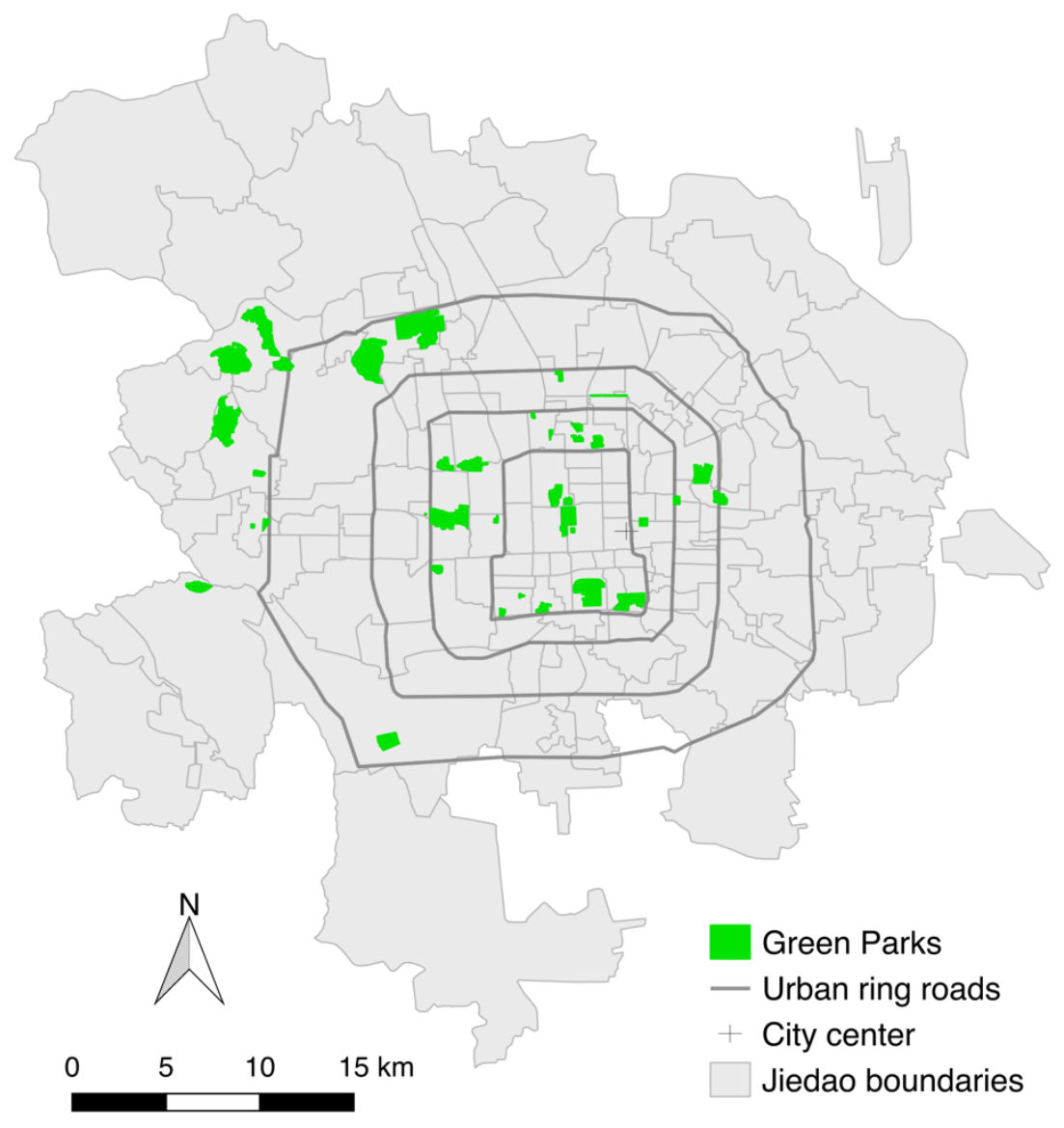

Figure 1. The distributions of key green parks, ring roads and neighbourhood boundaries in the study area. 


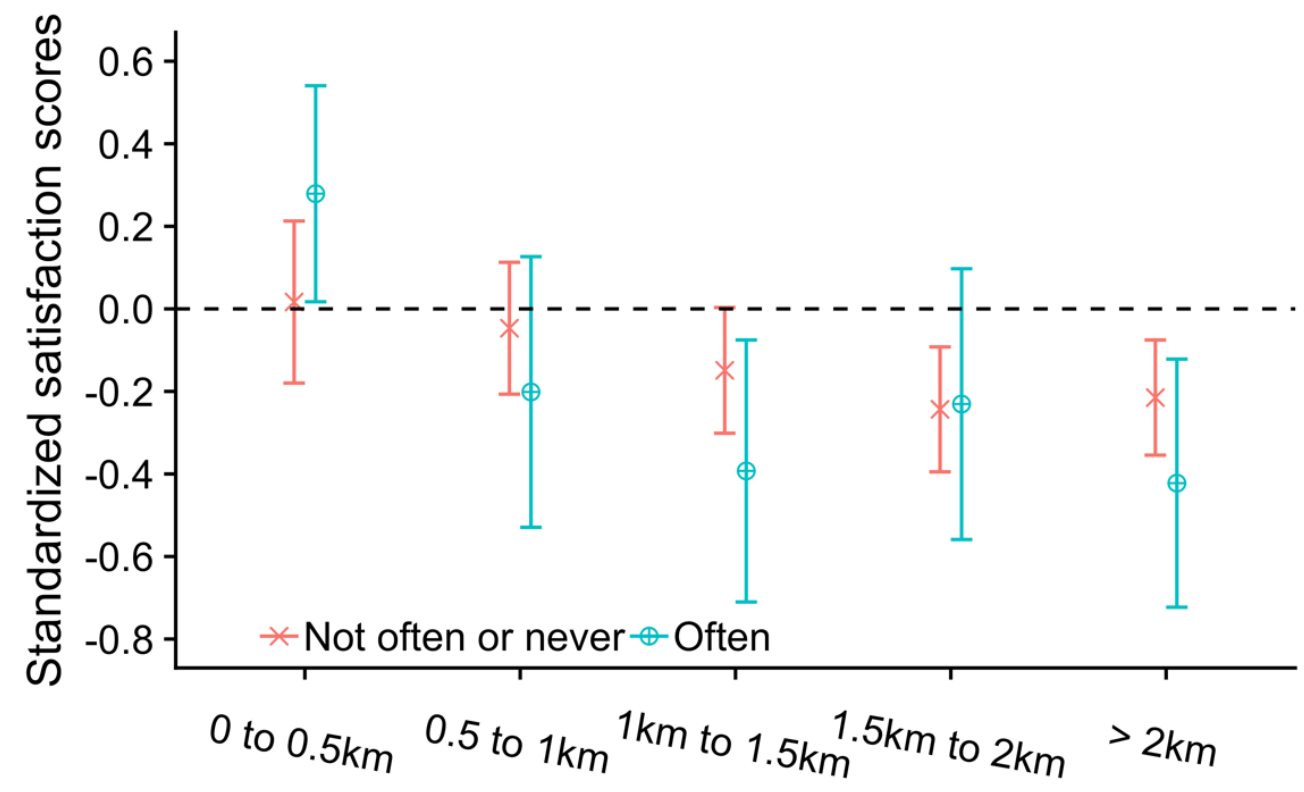

Figure 2. The adjusted residential satisfaction scores by park access and park use. 


\section{Author Statement}

WJ Wu and GP Dong: Conceptualization, Methodology, Investigation, Writing- Original draft,

Writing- review \& editing. YR Sun and Y Yun: Investigation, Writing- review \& editing, validation 